IBIMA Publishing

Journal of Marketing Research \& Case Studies

http://www.ibimapublishing.com/journals/JMRCS/jmrcs.html

Vol. 2014 (2014), Article ID 255150, 10 pages

DOI: $10.5171 / 2014.255150$

Research Article

\title{
Adolescents Sense of Community: A New Measurement Scale
}

\author{
Saoussen Abdelkader and Néji Bouslama
}

Faculty of Economics and Management of Tunis, Tunisia

Correspondence should be addressed to: Saoussen Abdelkader; saoussen_abdelkader@yahoo.fr

Received 24 December 2012; Accepted 28 December 2013; Published 24 January 2014

Copyright (C 2014 Saoussen Abdelkader and Néji Bouslama. Distributed under Creative Commons CC-BY 3.0

\begin{abstract}
The researches on the sense of community were always concentrated on the adult experiences and perceptions. That is why; there are sometimes some concerns about the visible lack of the teenager's sense of community, especially concerning the measurement of this concept. The object of this paper is to propose a new measurement scale designed for teenagers. Qualitative research was led with adolescent's community smokers to reveal the aspects of this concept and to propose a new structure of adolescent's sense of community.
\end{abstract}

Keywords: Sense of community; adolescents; trust; pleasure; identification.

\section{Introduction}

With the postmodern era and the new social links, a new need is born in consumers, reflected in developing a sense of belonging to a group. This latter tendency carries with it new social links between members, known as "sense of community". However, studies on sense of community have often focused on adults' experiences and perception. This led to concerns on a lack of interest in sense of community of adolescents and mainly on how to measure this concept. The aim of this paper is then to propose a measurement scale of sense of community devised for adolescents and which considers the differences between them and adults.

\section{Review of the Literature}

\section{Definition and Measurement of Sense of Community}

Currently, sense of community is one of the most studied psychological constructs and represents one of the most original and significant contributions in sociology (Tartaglia, 2006 in Imène B.Y, 2009, p 24)).

Nevertheless, despite its success, there is controversy on its definition. Accordingly, sometimes the concept is presented as the definition itself of a community (Garcia et al, 1999) or defined by its dimensions.

Studies of this concept started in 1974 with Sarasan, who was the first to propose the concept and defined it as "the feeling of belonging and be able to depend on a large community of partisans" (Proesholdbell, Roosa, Neweroff (2006, p9).

Initial theoretical and empirical proposals were developed in the US. Since 1990, several researchers from different countries and cultures started to focus on studying sense of community. Their studies provided a proof of the global nature of this construct. We cam mention the studies of Puddifoot $(1994,1996)$ in the UK, Prezza in Italy (Prezza and Costantini, 1998 ; Prezza,

Cite this Article as: Saoussen Abdelkader and Néji Bouslama (2014), "Adolescents Sense of Community: A New Measurement Scale," Journal of Marketing Research \& Case Studies, Vol. 2014 (2014), Article ID 255150, DOI: $10.5171 / 2014.255150$ 
Amici, Roberti and Tedeschi, 2001 ; Prezza, Costantini, Chiarolanza and Di Marco, 1999), Wiesenfeld, 1996 in Venezuela (Garcia, Giuliani and Wiesenfeld, 1999), and Fisher and sonn in Australia (1999, 2002) in Tartaglia (2006, p25).

The interest in this concept results from its ability to plan and evaluate social action. As predicted by Sarason (1974) in Tartaglia (2006, p25), sense of community relates to different indices of current lifa quality, like satisfaction (Prezza and Costantini, 1998); perception of peace and security (Perkins and Taylor, 1996), and social and political engagement (Chavis and Wondersman, 1990; Davidson and Cotter, 1989; Florin and Wondersman, 1954).

Then, researchers appreciated the important contribution gained diffusing this construct. Consequently, Mc Millan and Chavis (1986) reached a theoretical model that is more accurate and more articulate than that of Sarasan.

At the start, sense of community was considered from a geographic perspective and highlighted the link between individuals and their residential communities (Mc Millan and Chavis, 1989; Puddifoot 1994, Tartaglia, 2006). However, the study of this construct was to score its original and significant contribution to sociology. Traditional studies of sense of community focused more on territorial and geographical communities and few of them have focused on interest communities (classified by Gusfield (1975above).

Later, according to Peterson, Speer and Mc Millan $(2008$, p61) sense of community, a human phenomenon fundamental to a collective experience, has been studied in several contexts like the neighbourhood (Brodsky and Marx, 2001; Colombo and Stevenson, 1999; Perkins, Florin, Rich, Wandersman and Chavis, 1990); specific rehabilitation programs ( Herman, Onaga, Pernice - Duca, Oh and Ferguson, 2005); immigrants communities (Sonn, 2002); firemen (Cowman, Ferrari and Liao-Troth, 2004) and an international interest community (Ost, Zwikiewicz et Smith, 2002).
Recently, research on the subject expanded to include virtual communities (Kho and Kim, 2003; Markus and Blanchard, 2002; Butler B., Sproull, Kiesler and Kraut, 2002; Kim, Lee and Hiemstra, 2004 and Imene B.Y, 2009).

Sense of community then has been acknowledged its importance. It relates to the feeling of belonging to a community and to the awareness of such belonging (Heller and Aliii, 1984, cited by Kim and Kho, 2003; Newbrough and Chavis, 1986 in Imène B.Y (2009, p25).

The interest in sense of community raised controversies on its dimensions. In what follows, we will explore some proposals that attempted to measure this construct.

Sense of community, often termed psychological sense of community (PSC), has been often associated with Mac Millan and Chavis model (1986), which remains the main theoretical reference for researchers of this construct, yet there are many other studies which attempted to conceptualise and measure this construct (Bishp, Chertok and Jason, 1997; Buckner, 1988; Cantillon, Davidson and Schweitzer, 2003). (in Peterson, Speer and Mc millan, 2008).

Before 1986, sense of communjity has been defined by its measure and each study uses a unique measurement whose components are determined by a factor analysis, yet the principle behind item generation has never been put to discussion (Doolittle and Mc Donald, 1978; Glynn, 1981). Among the scales developed under this approach, we can mention the community satisfaction scale (1983), sense of community scale (Glynn, 19881), the neighbours cohesion index (Buckner, 1988) and recently the neighbourhood multidimensional scale (Skajaeveland et al, 1996).

In 1986, Mc Millan and Chavis presented their theory of the four components of PSC, which was founded on the one hand on a synthetic work of the first factor and on the other on the literature on group cohesion. 
Interviewing 1200 adults in a neighbourhood participation program, the authors reached 23 items representing sense of community grouped under four theoretical dimensions to produce the Psychological sense of community index (PSCI). However, because of its length, the use of this index was limited and consequently Chavis and his colleagues developed a sense of community index with 12 items (3 for each dimension), on a Tue or False scale, with the concept "building" as reference group.

This theory was revised by Mc Millan in 1996 and is till now the best foundation researchers refer to to understand communities. The four dimensions identified by Mc Millan D.W and Chavis D.M $(1986$, p6) are:

A. Membership: according to (1980, p 99), it is: "feeling the group in which they are and feeling themselves in this group enclose a set of individual attitudes and feelings, denoted by the word "membership"”.

B. Influence: It is a bidirectional concept. On the one hand, the member is influenced and attracted by the group and he/she should know about the group's activities (Peterson et Martens, 1972; Solomon, 1960; Zander and cohen, 1955). On the other hand, cohesion influences the group's aptitude to influence its members (kelley and Volkart, 1952; Kelley and Wondruff, 1956).

C. Needs Fulfilments and Integration; it is the feeling that our needs are found and fulfilled by belonging to the group or the perception that members needs are found by group members. With sense of community, groups look for linking themselves. They see as if others needs are their own needs (Cf. Riley, 1970; Zander, Natsoulas and Thomas, 1960).

D. Shared Emotional Connexion: it is the feeling of being attached or building up a link or engagement in stories, places or experiences shared by members. It is also feeling of warmth and comprehension between members of the group.

Sense of community theory has been subject of several qualitative studies (Brodsky, 1996; Plas and Lewis, 1996). Among the different measures in line with Mc Millan and Chavis' theory, there was only the sense of community index (SCI) (Perkins, Florin, Rich, Wandersman et Chavis, 1990) able to measure the four components of psychological sense of community. (Petreson N. Andrew, Speers Paul and Mc Millan Chavis, 2008, p69).

Recently, Peterson, Speer and Mc Millan (2008) have conducted a study to develop and validate a brief scale measuring sense of community, known as Brief Sense of Community Scale (BSCS) and another examining the relationship with set of theoretical variables.

\section{Sense of Community of Adolescents}

Adolescence has often been known by a period when individuals start exploring and examining psychological characteristics in view of discovering their realities and how they adapt to their social environment (Laurence Steinberg and Amanda Sheffield Morris (2001, p91). This latter stage helps them create a social identity that manifests itself in the considerable interest in group influence and other aspects of group behavior (See Brewer et Brown, 1998 in Wendy Wood (2000, p 557)).

From a social identity perspective, when individuals are members of a group, this latter serves as a reference for social comparison and individuals may adopt attitudes and beliefs of members as prototypes. Then, groups exert an influence over behavior which goes through some processes in particular for adolescents known as sense of community.

Moreover, using social identity theory, Abrams and Hogg, 1990; Tajfel and Turner, 1990, Ost et al. (2002) in Obst, Zinkiewicz and Smith (2002, p 107) examined the role of identification with psychological sense of community and found that this latter 
represents an important aspect separate from the dimensions of sense of community as presented in Mc Millan and Chavis model (1986).

Studies of sense of community have often focused on adults' experiences and perception. However, few have done so on sense of community of adolescents. Although recognition of the effects of communities on adolescents' development has increased with developmental studies (Bornfenbrenner, 1989; Cauffman and Steinberg, 1995; Steinberg, 1995) and community studies (Seidman, 1991), according to Pretty Conroy Grace M.H., Dugay Jason, Fowler Caren et Williams Diane (1996, p365), we still know less about psychological sense of community of adolescents.

Studies of adolescents development suggest that they benefit differently from the opportunities of being involved in a community (Catalano, Loeber and Mc Kinney, 1999; Maton, 1990; Youniss, McLellan and Yates, 1997). However, most studies of sense of community and social cohesion have neglected experiences of adolescents.

Another concern relates to measurement of the construct in adolescents using tools designed for adults (Chiuper and Pretty, 1999; Pretty, Conroy, Dugay, Flower and William, 1996). Although the studies of Pretty and his colleagues (Pretty, Andrewes and Collett, 1994) encourage the use of Mc Millan and Chavis model and adoption of their measurement of psychological sense of community in adolescents, Evans (2007) in Evans, Scot D. (2007, p 694) assumes that "it's important to understand that adolescents perceive community differently from adults, measures of sense of community should take into account this difference".

In this line of thinking, we noted that sense of community index devised to measure the construct in adults tends to neglect constructs that are important for young people, like fun and safety (Chiuper et al. 1999; Chiuper and Pretty, 1999; Patten, 2000), although "it provides a foundation for developing scales appropriate to adolescents that are recently in progress" Chipuer, pretty, Delore, Miller, Power, and Rumstein, in Press in Chiuper, Pretty (1999, p 648).

Moreover, some influence items are not appropriate to adolescents, as "developmental theories admit the other three dimensions of sense of community except for the dimension influence. For instance, Erikson (1968) stops at the importance of peer attachment as a crucial part of adolescents' development" (Chiuper, Pretty, 1999, p648).

The results of previous research on the value of sense of community in adults, shown in terms of participation in community activities, neighborhood or work environment ..., encouraged other researchers to explore the usefulness of this concept for adolescents I the context of the neighborhood and also the school, which is the community in which adolescents spend most of their time (Pretty Conroy Grace M.H, Andrewes Lisa, Collett Chris, 1994, p 347).

Researchers assumed that sense of community is involved in developing adolescents like it does for adults.

During the life cycle of adolescents, many senses of communities develop and play an important role in understanding their behavior. Then, the first sense of community, after the family, is created at school and its environment which helps facilitate or hinder the adolescent's successful development (Cartlard et al, 2003, Roeser, Midgley and Urdan, 1996; Shaps and Solomom, 2003 in Alessio vieno, Massimo santinello, Massimiliano Pastore, douglas Perkins $(2007,179)$ ).

At this level, many studies have been conducted to show that school environment, which is perceived as a welcoming and supportive environment, relates to several models of cognition, affection and behaviour (Bateman, 1998; Battistich, Kim, Watson....), hence the emergence of the concept school sense of community to describe the psychological 
aspects of school and the groups that fulfil the needs of belonging and support (Bateman, 2002 in Alessio vieno, Massimo santinello, Massimiliano Pastore, douglas Perkins (2007, p179).

School environment, which consists of friends, bands, buddies or even peers may also influence the development and behaviour of adolescents. Many important studies have examined how these groups influence them and reached to findings that peers influence adolescents in two ways: positively and negatively. Then, they can influence their academic achievement and their pro-social behaviour (Mounts and Steinberg, 1995; Wentzel and Caldwell, 1997) as well as use of alcohol and drugs, smoking and delinquency (Urberg et al, 1997).

Peers influence each other through effect of pressure or constraints. Most adolescents are influenced by their peers because they admire them and respect their opinions (Susman et al, 1994). Added to this is that adolescents and their friends are often the same not because they influence each other but also they tend to choose friend with the same behaviour, attitudes and identities (Aaker et al, 1998, Hogue and stenberg, 1995).

The results of these studies lead us to deduce the importance of the need to belong and to establish links for adolescents. Accordingly, sense of community becomes central for the psychological well-being of the individual (Sarason, 1974). Then, "sense of belonging in members, the fact of becoming important for each other and sense of shared trust members need will be found in a commitment to be together" (Mc Millan and chavis, 1986 in Alessio vieno, Massimo santinello, Massimiliano Pastore, douglas Perkins (2007, p179)) and serves what is known as sense of community.
Groups of young people represent a community which generally consists of alienated individuals. Their development is based on the experiences shared between members once separated from traditional social systems and on emotional and physical security that members provide for each other (Cloward and Ohlin, 1960 in Mc Millan and Chavis (1986, p17)), found in sense of community. Then, groups develop symbolic frontiers that serve their protection and help them insure their integration and differentiation from others.

\section{Research Design and Methodology}

Sense of community was not studied in the context of adolescents. We conduct a qualitative study through 12 semi-directive interviews with a community of smoking adolescents ( 5 boys and 7 girls aged between 13 and 20). The interview focuses on the relationship members have with the group and the feelings they feel about this community.

Before proceeding to this exploratory study, the brief sense of community scale of Peterson, Speer and Mc Millan (2008) was translated into French in order to detect the different dimensions of the scale found in the literature in the interviewed discourse. The results confirm the presence of the three dimensions, in addition to other dimensions related to trust, selfidentification and pleasure/fun. The retained 12 items have been submitted to a pre-test to check for their comprehension and clarity before operationalising the study.

The following table presents the structure retained after the exploratory study (the first eight items correspond to the brief sense of community scale, to which we added the four remaining items generated by the exploratory study).

Table 1: Dimensions of Sense of Community of Adolescents 


\begin{tabular}{|l|l|l|}
\hline Concepts & Name & Items label \\
\hline Needs fulfillment & SC1 & I can have what I need in this group. \\
\hline Needs fulfillment & SC2 & This group helps me fulfill my needs. \\
\hline Belonging & SC3 & I have the impression I am a member of this group. \\
\hline Belonging & SC4 & I belong to this group. \\
\hline Influence & SC5 & I influence how the group functions. \\
\hline Influence & SC6 & People in this group are good influencers of each other. \\
\hline Emotional connection & SC7 & I have the impression I am connected to the group. \\
\hline Emotional connection & SC8 & I have good relationships with the others in the group. \\
\hline Trust & SC9 & I feel safe in this community. \\
\hline Trust & SC10 & I tend to defend this group. \\
\hline Identification & SC11 & I identify with the objectives and values of the community. \\
\hline Pleasure/Fun & SC12 & This community gives me pleasure/fun and joy. \\
\hline
\end{tabular}

During data collection, we interviewed adolescents members of a "smokers community". 100 people participated in the survey for the exploratory factor analysis and 380 people participated in the survey for the confirmatory factor analysis.

\section{The Results}

\section{The Exploratory Factor Analysis}

We conducted a principal component analysis (PCA) on the first sample to purify sense of community scale. The results yielded a three-dimensional structure with 12 items. This structure grouped the first four items of "needs fulfillment", "belonging" and "self-identification". The items seem related because if we feel we belong to a community, this is true because we believe that this latter meets our expectations and then it fulfills our needs. Moreover, belonging to a group means identifying with it. Many theorists (Fisher and Sonn, 1999; Pudifoot, 1995) suggest that the different levels of psychological sense of community may be understood in terms of degrees with which members identify themselves to the community. This dimension which combines belonging, identification and needs fulfilment may be called "membership".

The second dimension groups the items of influence and trust. This combination is not surprising to us because in order to influence and be influenced in $a$ community, there should be a minimum of trust. Influence "is when the individual feel that his/her position in the community is recognised and that his/her presence makes the difference" (Imène B.Y, 2009). To reach this level, members should trust each other. This dimension may be called "influence".

The last dimension groups the items "emotional connection" and pleasure/fun. This is explained by the fact that the individual is pleased and amused when he/she "thinks that he/she shares common stories and experiences" (Imène B.Y, 2009). We retain the name of "emotional connection" for this dimension.

The PCA helped reveal a KMO coefficient of 0.784 with a significant Barlett's sphericity test. The dimensions retained explain $74.862 \%$ of total variance. The reliability analysis yielded to a Cronbach's Alpha as high as 0.850 for the "membership" dimension, 0.882 for the "influence" dimension and 0.7. 9 for the "emotional connection" dimension

\section{The Confirmatory Factor Analysis}

The first confirmatory factor analysis of our scale did not show good fit results. The coefficients obtained of the different absolute, incremental and parsimony indices are within norms. We then had to make some modifications by adding relationships between error terms and some items. The second confirmatory factor analysis, however, suggests that we eliminate items 2 and 8 which had factor loadings $<0.4$ (see appendix).

Their elimination resulted in acceptable fit values summarised as follows: 
Table 2: Sense of Community Scale's Fit Quality

\begin{tabular}{|l|l|l|l|l|l|l|l|l|}
\hline $\mathbf{X}^{\mathbf{2}}$ & $\mathbf{X}^{\mathbf{2}} / \mathbf{d d l}$ & GFI & AGFI & RMR & RMSEA & TLI & CFI & BIC \\
\hline $\begin{array}{l}302.664 \\
\text { DD22 } \\
\text { P 0.000 }\end{array}$ & 13.757 & 0.869 & 0.731 & 0.027 & 0.183 & 0.800 & 0.878 & $462.288 / 312.308$ \\
\hline
\end{tabular}

The results of CFA, reliability and

convergent validity are as follows:

Table 3: CFA of SC Scale, Posteriori (A)

\begin{tabular}{|c|c|c|c|c|c|c|c|}
\hline DIMENSION & Items & $\begin{array}{c}\text { Cont. Fact. } \\
\text { stand }\end{array}$ & SMC & c.r. & $\mathbf{P}$ & $\begin{array}{c}\rho \\
\text { Jöreskog }\end{array}$ & $\rho_{v c}$ \\
\hline \multirow[t]{3}{*}{ Membership } & SC1 & 0,696 & 0.484 & 15,018 & 0.000 & \multirow{3}{*}{0.822} & \multirow{3}{*}{0.606} \\
\hline & SC3 & 0,847 & 0.718 & 19,750 & 0.000 & & \\
\hline & SC11 & 0,787 & 0.619 & 17,714 & 0.000 & & \\
\hline \multirow[t]{4}{*}{ Influence } & SC5 & 0,733 & 0.537 & 15,914 & 0.000 & \multirow{4}{*}{0.828} & \multirow{4}{*}{0.542} \\
\hline & SC6 & 0,722 & 0.522 & 15,489 & 0.000 & & \\
\hline & SC9 & 0,822 & 0.676 & 18,612 & 0.000 & & \\
\hline & SC10 & 0,674 & 0.454 & 14,173 & 0.000 & & \\
\hline \multirow{2}{*}{$\begin{array}{l}\text { Emotional } \\
\text { Connection }\end{array}$} & SC7 & 0,860 & 0.740 & 19,106 & 0.000 & \multirow{2}{*}{0.727} & \multirow{2}{*}{0.576} \\
\hline & SC12 & 0,642 & 0.412 & 13,287 & 0.000 & & \\
\hline
\end{tabular}

As for discriminant validity, it is satisfactory if variance shared between the constructs is inferior to the variance shared between the constructs their measure
(Fornell and Larcker, 1981). Then, convergent validity of each construct should be superior to the squared correlations with the other constructs.

Table 4: Discriminant Validity of Sense of Community Scale

\begin{tabular}{|l|l|l|l|}
\hline & Membership & Influence & Emotional Connection \\
\hline Membership & $\mathbf{0 . 6 2 3}$ & & \\
\hline Influence & 0.844 & $\mathbf{0 . 5 5 7}$ & \\
\hline Emotional Connection & 0.855 & 0.885 & $\mathbf{0 . 5 9 0}$ \\
\hline
\end{tabular}

\section{Goodness of Fit of the Structural Model}

We tested our first order structural model consisting of the three dimensions membership, influence and emotional connection. The results indicate that correlation between the three dimensions are high and exceed 0.8 . Then, we moved to test the second order model.

Tableau 5: Correlation between Dimensions of Sense of Community

\begin{tabular}{|c|c|c|}
\hline & & Estimate \\
\hline MEMBERSHIP & <--> INFLUENCE & 0,916 \\
\hline INFLUENCE & <--> EMOTIONAL CONN & 0,812 \\
\hline MEMBERSHIP & $<-->$ EMOTIONAL CONN & 0,941 \\
\hline
\end{tabular}

By testing the second order structural model, we noticed that saturation of items in each dimension are satisfactory. Moreover, correlations between the different dimensions to the second order construct are significant $(>0.9)$. The model's fit indices are not good but they indicate an enough satisfactory fit quality. The results are summarised in the following Table. 
Table 6: Second Order Structural Model Test

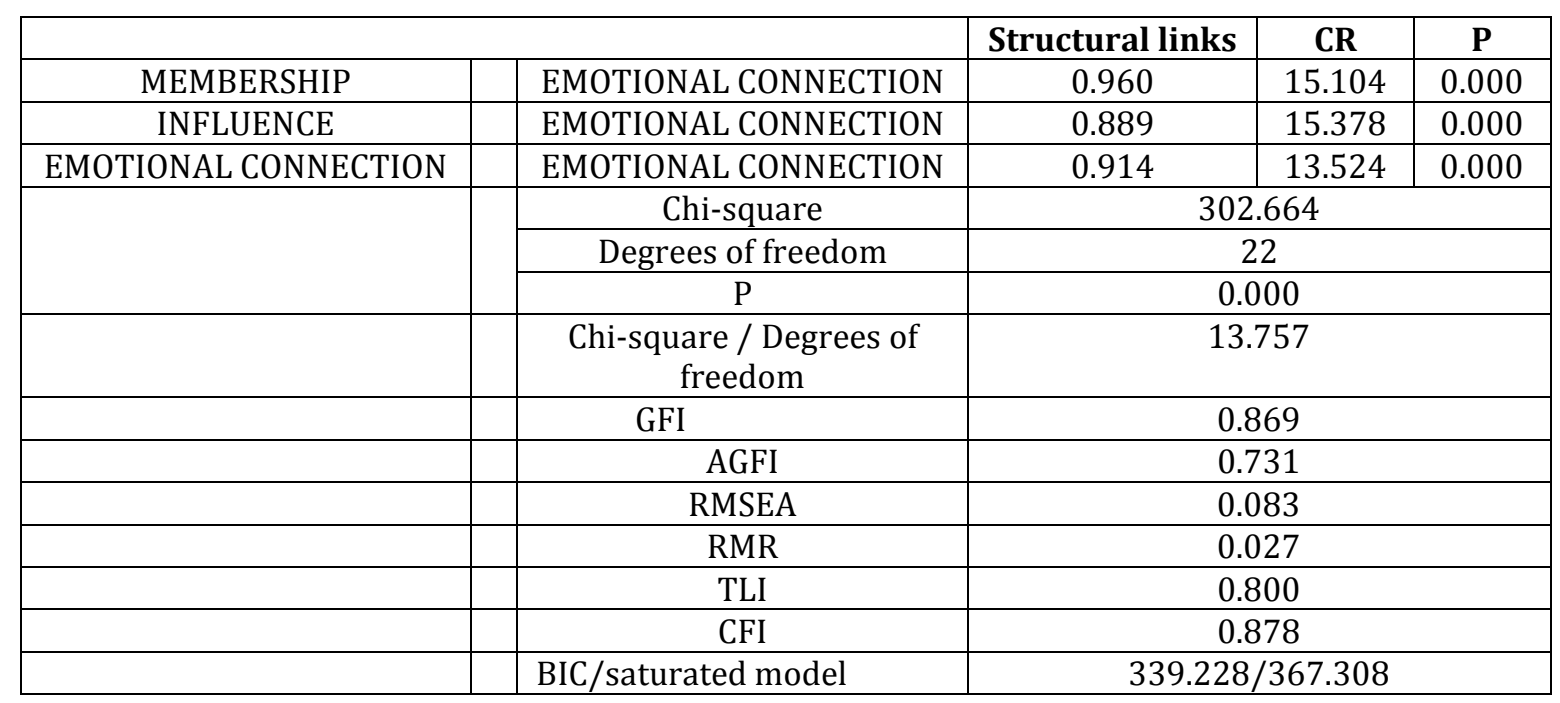

\section{Conclusions and Discussions}

Although recognition of the effects of communities on development of adolescents has increased with developmental studies (Bornfenbrenner, 1989; Cauffman and Steinberg, 1995; Steinberg, 1995) and community studies (Seidman, 1991), according to Pretty Conroy Grace M.H., Dugay Jason, Fowler Caren and Williams Diane (1996, p365) still less is known empirically on psychological sense of community in adolescents and in particular its measurement. In this paper, we were able to answer the controversies on sense of community and its measurement in adolescents. Our results confirm first the relevance of sense of community in adolescents. This indicates its importance and the merit to be the focus of researchers who may further examine its factors and consequences in terms of adolescents behaviour and attitudes...

Our results point to a three-dimensional structure for sense of community. This structure is similar to that proposed by Mc Millan and Chavis (1986) and which consists of four components (belonging, influence, needs fulfilment and emotional connection). Ours is different as it integrates this latter and some other dimensions important for adolescents. Structure of sense of community in adolescents is different from that in adults. It includes additional items to those in the literature for adults and which relate to trust, identification and pleasure/fun.

Our results could not identify these components as dimensions of sense of community, however we cannot neglect them as adolescents may have them in their sense of community. Adolescence is a difficult period for young people. These latter seek to escape their parents control and approach more and more their peers, who contribute in forming their personalities, giving them more selfconfidence and satisfying their identification needs. During adolescence, young people express a strong need to belong to a group. This latter helps them to take distance from their parents and find their own identities (Duclos G, 2004).

Adolescence finds in its community a pleasant environment full of fun because with friends adolescents often look for transgressing the rules imposed by parents and free themselves from parents' control of their reactions and decisions.

Moreover, young people develop a strong sense of belonging by creating links with their friends. This emotional experience reinforces their identification with the group. Certainly, "when the child feels accepted and esteemed by his/her peers, 
he/she confirms his/her identity, and trust to others increases. He/she looks for the occasions or situations where he/she is in a group, because he/she feels confidence and knows that he/she will be recognised" (Duclos G, 2004).

Our results helped us better understand adolescents and their way of perceiving sense of community. Accordingly, in practice, our study may serve many professionals. In marketing, firms interested in communities of adolescents should develop communication, positioning and segmentation strategies that consider the aspects the most important for these communities in order to better target their offers.

In the social field, understanding sense of community in adolescents and distinguishing it from that of adults help better understand social behaviour of this age category.

Our study is not without limitations. We limited ourselves to the study of one type of community of adolescents (face-to-face community) which could not allow us to generalise our results. Future research may focus on interest communities, brands communities, and political or cultural communities and may unveil other aspects of sense of community. Moreover, a comparative study of different types of senses of communities will be fruitful. We limited ourselves also to Tunisian adolescents. An intercultural study would be interesting to understand functioning of sense of community in different cultures.

\section{References}

Ben Yahia, I. (2009). 'Proposition d'une Échelle de Mesure du Sentiment Envers une Communauté Virtuelle,' Communications of the IBIMA, volume 10

Chiuper, H. M. \& Pretty, G. M. H. (1999). “A Review of the Sense of Community Index: Current Uses, Factor Structure, Reliability and Further Development," Journal of Community Psychology, vol 27, n6
Duclos, G. (2004). L'estime de Soi, un Passeport pour la Vie, 2e édition, coll. Parents, Montréal, Éditions de l'Hôpital Sainte-Justine.

Evans, S. D. (2007). "Youth Sense of Community: Voice and Power in Community Contexts," Journal of Community Psychology, vol 35, n 6, (693709)

McMillan, D. W. \& Chavis, D. M. (1986). "Sense of Community: A Definition and Theory," Journal of Community Psychology, volume 14, January, (6-23)

Muccielli. (1980). "Sentiment d'appartenance," Consulté en 2009 sur le Lien:

www.uquebec.ca/edusante/sociale/imp_se ntiment_appartenance.htm

Obst, P., Zinkiewicz, L. \& Smith, S. G. (2002). "Sense of Community in Science Fiction Fandom Part 2: Comparing Neighborhood and Interest Group Sense of Community," Journal of Community Psychology, vol 30, n 1, (105-117)

Peterson, N. A., Speer, P. W. \& McMillan, D. W. (2008). "Validation of a Brief Sense of Community Scale : Confirmation of the Principal Theory of Sense of Community," Journal of Community Psychology, vol 36, $\mathrm{n}^{\circ} 1, \mathrm{p} 61-73$

Pretty,G. M. H., Andrewes, L. \& Collett, C. (1994). “Exploring Adolescents' Sense of Community," Journal of Community Psychology, vol 22, Octobre, (346-358)

Pretty,G. M. H., Conroy, C., Dugay, J., Fowler, C. \& Williams, D. (1996). "Sense of Community and its Relevance to Adolescents of All Ages," Journal of Community Psychology, vol 24, n4, (365379)

Proesholdbell, R. J., Roosa, M. W. \& Neweroff, C. J. (2006). "Component Measures of Psychological Sense of Community among Gay Men," Journal of Community Psychology, V34, n1 
Steinberg, L. \& Morris, A. S. (2001). "Adolescent Development," Annual Review of Psychology, V52, (Research Library p83110)

Tartaglia, S. (2006). "A Preliminary Study for a New Model of Sense of Community," Journal of Community Psychology,V34, n1

Vieno, A., Santinello, M., Pastore, M. \& Perkins, D. D. (2007). "Social Support, Sense of Community in School, and SelfEfficacy as Resources during Early Adolescence: An Integrative Model," American Journal of Community Psychology, vol 39, (177-190)

Wood, W. (2000). "Attitude Change: Persuasion and Social Influence," Annual Review of Psychology, volume 51, Research Library (539-570) 